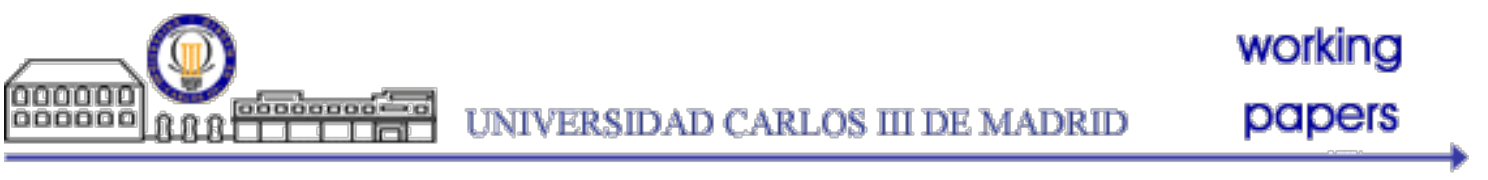

UC3M Working Papers

Statistics and Econometrics

16-04

ISSN 2387-0303

April 2016
Departamento de Estadística

Universidad Carlos III de Madrid

Calle Madrid, 126

28903 Getafe (Spain)

Fax (34) 91 624-98-48

\title{
Remittances in Mexico and their Unobserved Components
}

\author{
Francisco Corona $^{\mathrm{a}}$, Pedro Orraca ${ }^{\mathrm{b}}$
}

\begin{abstract}
The present study aims to determine the common trends and the permanent and transitory components of remittances received by Mexican households. This is done by estimating a small Dynamic Factor Model (DFM), using the approach first proposed by Gonzalo and Granger (1995), determining the number of common trends subject to the cointegration results. The study also shows the similarities between this small DFM with respect to large DFM, which are widely used in the econometric literature. The results indicate the presence of one cointegration relationship. Consequently, there are four common trends. These common factors are negatively dominated by Mexico's economic activity and positively by the U.S. industrial production. The effects of the exchange rate and the U.S. unemployment rate are positive, but less relevant. This economic scenario leads to remittances exceeding its permanent component.
\end{abstract}

Keywords: Remittances, P-T decomposition, Dynamic Factor Models.

\footnotetext{
${ }^{a}$ Department of Statistics, Universidad Carlos III de Madrid.

${ }^{\mathrm{b}}$ Department of Economics, University of Sussex.
} 


\title{
Remittances in Mexico and their Unobserved Components
}

\author{
Francisco Corona ${ }^{1}$ and Pedro Orraca ${ }^{2}$ \\ ${ }^{1}$ Departament of Statistics, Universidad Carlos III de Madrid \\ ${ }^{2}$ Department of Economics, University of Sussex
}

April 2016

\begin{abstract}
Resumen
Este estudio tiene como objetivo determinar las tendencias comunes y los componentes permanentes y transitorios de las remesas recibidas por los hogares mexicanos. Esto se hace mediante la estimación de un modelo de factores dinámicos (DFM) de baja escala, en base a la metodología propuesta originalmente por Gonzalo y Granger (1995), determinando el número de factores comunes sujetos a los resultados de cointegración. Adicionalmente, mostramos las similitudes entre un DFM de baja escala con respecto a un DFM de larga escala. Los resultados indican la presencia de una ecuación de cointegración. Consecuentemente, existen cuatro factores comunes. Estos factores comunes son dominados negativamente por la actividad económica de México y positivamente por la producción industrial de Estados Unidos. Los efectos del tipo de cambio y la tasa de desempleo de Estados Unidos son positivos, pero menos relevantes. Este escenario económico propicia que las remesas excedan su componente de largo plazo.
\end{abstract}

\begin{abstract}
The present study aims to determine the common trends and the permanent and transitory components of remittances received by Mexican households. This is done by estimating a small Dynamic Factor Model (DFM), using the approach first proposed by Gonzalo and Granger (1995), determining the number of common trends subject to the cointegration results. The study also shows the similarities between this small DFM with respect to large DFM, which are widely used in the econometric literature. The results indicate the presence of one cointegration relationship. Consequently, there are four common trends. These common factors are negatively dominated by Mexico's economic activity and positively by the U.S. industrial production. The effects of the exchange rate and the U.S. unemployment rate are positive, but less relevant. This economic scenario leads to remittances exceeding its permanent component.
\end{abstract}

JEL Classification: C38, F24, F44

Keywords: Remittances, P-T decomposition, Dynamic Factor Models. 


\section{Introduction}

Mexico is an upper middle income country and the second largest economy in Latin America. In 2014, the country's population totalled an estimated 123.8 million and its Gross Domestic Product (GDP) per capita stood at 10,361.3 U.S. dollars (World Bank, 2015).

After decades of sustained growth, Mexico's economy began decelerating in the late 1970s. Following a sovereign default in 1982 which resulted in the collapse of the Mexican peso and a sharp reduction in GDP, the country was forced to make significant changes to its economic structure. These included an aggressive reduction of the role of the state in the economy and the embrace of global markets by entering the General Agreement on Tariffs and Trade in 1985 and signing the North American Free Trade Agreement in 1993 (Hanson, 2010).

Mexico's economic transformation was successful in reducing inflation, maintaining fiscal discipline, reducing its external debt burden, and increasing trade as a share of GDP (Hanson, 2010, p. 988). Nonetheless, this was not accompanied by high levels of economic growth, where between 1982 and 2014 the country's GDP grew at an average annual rate of $2.3 \%$ (World Bank, 2015).

To escape economic hardships in Mexico or because they are in search of a better life, a large fraction of the country's population has migrated to the United States. In 2010, an estimated 11.2 million Mexicans were residing in the U.S., rising to $14.2 \%$ of Mexico's working age population and $6.3 \%$ of the U.S. labour force. ${ }^{1}$

Remittances represent a significant source of income for Mexican households, accounting for $1.8 \%$ of Mexico's GDP in 2012. Moreover, remittances represent the second most important component of the country's trade balance, only behind oil revenue (INEGI, 2015). Since 2006, remittances exhibit an increasing trend, characterised by a slight drop at the start of the world financial crisis in 2008.

Due to its relationship with household income, migration and economic growth, it is relevant to analyse the determinants of remittances in order to identify the macroeconomic conditions and public policies that affect their flows and movements.

Although previous studies have examined the dynamics between remittances and their determinants (see, e.g. Elbadawi and Rocha, 1992, Castillo, 2001, Vargas-Silva and Huang, 2006, Islas and Moreno, 2011), their possible stochastic common trends and permanent

\footnotetext{
${ }^{1}$ Figures based on the 2010 Mexican Census and the 2010 American Community Survey.
} 
and transitory components have not yet been explicitly analysed. This is relevant since it allows identifying the common features with respect to their covariates, as well as their specific long-run behaviour and transitory dynamics.

Studies that have focused on Mexico include Coronado (2009) and Castillo et al. (2011). Nevertheless, the former is a univariate empirical analysis that does not consider the relationships with the theoretical determinants; while the latter relies on bivariate exercises to determine the long-run and short-run relationships that remittances share with a group of variables, but does not consider the multivariate dynamics. Thus, while the literature has identified the macroeconomic determinants of remittances and their stochastic behaviour, it has not linked these two approaches. The present study uses an econometric methodology that satisfies both of these points.

It is known that macroeconomic variables are generally $I(1)$, frequently cointegrated (Kunst and Neusser, 1997), and that cointegrated variables involve a factor representation (see, e.g. Stock and Watson, 1988, Vahid and Engle, 1993, Gonzalo and Granger, 1995). These facts allow us to specify remittances in a multivariate system, where the dynamics are represented through non-stationary common factors and a stationary component, similar to the Dynamic Factor Models (DFM) when the factors are random walks.

DFM were first introduced in Economics by Geweke (1977) and Sargent and Sims (1977) and extended for large systems by Forni et al. (2000, 2004, 2005) and Stock and Watson $(2002 \mathrm{a}, \mathrm{b})$ for stationary variables. ${ }^{2}$ The common components in large DFM are commonly estimated using Principal Components (PC) and the theoretical results are developed assuming that the number of time series, $N$, and the number of observations, $T$, jointly tend to infinity, obtaining consistent estimations of the common components (Bai, 2003). ${ }^{3}$ However, in our case the multivariate system is structural in the sense that the conceptual framework determines the variables in the model. It is our interest to estimate a small DFM where the $I(1)$ common factors allow us to distinguish between the long-run and short-run dynamics. ${ }^{4}$

The present study aims to determine the common trends and the permanent and transitory components of remittances received by Mexican households. We specify a DFM

\footnotetext{
${ }^{2}$ Non-stationary DFM are analysed by Bai (2004), Bai and Ng (2004), Peña and Poncela (2004), Peña and Poncela (2006), Lam and Yao (2011, 2012), and Choi (2012), among others.

${ }^{3}$ Empirically, Bai (2003) shows that since $N=25$ and $T=50$ we can consistently estimate the common components.

${ }^{4}$ We use the term small to distinguish from large systems.
} 
using the concepts first presented by Gonzalo and Granger (1995), therefore establishing the link between the specification of the standard DFM and the P-T decomposition proposed by the referred authors.

The study proceeds as follows. Section 2 presents the literature review and the conceptual framework. Section 3 describes the model and the estimation procedure. Section 4 discusses the main results. Section 5 concludes.

\section{Literature Review}

The decision to remit is usually preceded by migration. People migrate due to different reasons related to income maximization, minimizing risks to personal or family income, or overcoming capital constraints, among others (Orraca, 2015).

The theoretical literature that has studied the motives for remitting has mainly centred on altruism and exchange (see, e.g. Barro, 1974, Becker, 1974, Bernheim et al., 1985). Altruistic remittances occur because the donor is interested in the recipient's utility. On the other hand, remittances driven by exchange are given in order to compensate the recipient for providing different services to the donor, which may include providing different types of informal care or obeying parental rules (Juarez, 2009).

Additional motives for remitting include a desire to secure access to economic resources such as an inheritance or the longing to invest in assets in order to self-insure or to earn higher economic return (see, e.g. Bernheim et al., 1985, Lucas and Stark, 1985, Durand et al., 1996). Individuals may also remit because the act of giving provides them utility or to comply with social norms (Jensen, 2003). Finally, remittances may also be a product of informal risk-sharing agreements between donors and recipients (Rosenzweig, 1988).

Concerning the macroeconomic determinants of remittances, the review put forward by Islas and Moreno (2011) found that the main covariates that explain the flow of remittances are economic activity of the migrant's host and home economies, the business cycle of the host economy, the differential between the interest rates of both countries, the wages of the host and home economies, the inflation rate of the home economy, the unemployment rate of the host economy, the stock of immigrants, exchange rates, the federal funds rate, money supply, economic stability, foreign investment and time spent in the host country. Empirically, the authors use a set of Vector Error Correction Models (VECM) and analyse the long-run relationship between remittances and their determinants. The results show 
that investment decisions are more important than altruistic issues.

Further empirical applications for Mexico include Castillo (2001), who performs a cointegration exercise to determine the long-run relationship between remittances, Mexico's and the U.S. GDP, and the real bilateral exchange rate. The results show a negative sign with respect to Mexico's GDP and the exchange rate and a positive sign for U.S. GDP. Vargas-Silva and Huang (2006), using information on federal funds rates, money supply, the consumer price index, and the unemployment rate for the U.S. and exchange rate and inflation rate data for a group of Latin American economies, observe that macroeconomic conditions of the host economy are more relevant than those of the home country. Coronado (2009) uses unobserved components extracting the business cycle of the U.S., relating it with the cyclical components of remittances received by Mexico and El Salvador. The author finds that the stationary components are strongly pro-cyclical with the output fluctuations of the home country. Castillo et al. (2011) evaluate whether macroeconomic conditions determine the amount of remittances sent to Mexico from the U.S., using the concepts given by Vahid and Engle (1993) which, subject to the cointegtration results, statistically define the cofeature vectors. The results indicate that employment in the U.S. and credit and inflation rates in Mexico significantly affect remittances in the longrun. Moreover, the real exchange rate and remittances are found to be positively related in the long-run, but negatively associated in the short-run. Mendoza (2011), using panel data, evaluates whether remittances can function as a counter cyclical mechanism for a contraction phase of the business cycle in Mexico. The results show that remittances are positively correlated with the business cycle, indicating that it is difficult to think that remittances are a stabilising tool of the business cycle.

Consequently, it can be observed that the different studies for Mexico are mainly based on cointegration exercises because the variables of the system are $I(1)$ and they share at least one long-run relationship. However, the estimation of the VECM is in first differences and although they consider long-run relationships, they do not analyse the stochastic common trends or the $I(1)$ common factors and the specific transitory components for each variable of the system. The estimation of the common factors is very important since it allows recovering the common long-run behaviours between variables. This idea denotes a DFM, which is commonly used to extract the common factors in large systems of variables. 
There is an extensive literature on DFM for the case of stationary variables (see, e.g. Geweke, 1977, Sargent and Sims, 1977, Engle and Watson, 1981, 1983, Sargent, 1989, Stock and Watson, 1989, Quah and Sargent, 1993). These studies estimate the common components using the time-domain maximum likelihood via the Kalman filter. Furthermore, given the availability of economic time series which have been collected for decades by statistical agencies, large DFM have been popularised in several empirical applications (see surveys by Bai and Ng, 2008, Stock and Watson, 2011, Breitung and Choi, 2013). The basic idea of large DFM is to extract the common factors using PC to transform data to stationarity, determining the number of factors through some information criteria or studying the behaviour of the eigenvalues of the sample covariance matrix (see, Bai and Ng, 2002, Alessi et al., 2010, Onatski, 2010). It is clear that these approaches do not recover long-run information. Therefore, non-stationary DFM are analysed by Bai (2004), Bai and Ng (2004), Lam and Yao (2011, 2012), Choi (2012), among many others, but always in the context of large systems. For small systems, there are some alternatives representations as the ones put forward by Stock and Watson (1988), Vahid and Engle (1993) and Gonzalo and Granger (1995) and Peña and Poncela (2004, 2006).

In this study, we use the notation of a DFM in the context of the factor model proposed by Gonzalo and Granger (1995). We use this approach given that it allows us to establish the time series through common factors and recover the permanent and transitory components in a multivariate system when $N$ is small.

\section{Econometric Model}

In this section we develop a small DFM to determine the common factors of Mexican remittances using the results given by Gonzalo and Granger (1995), which allow us to make the P-T decomposition for each variable of a multivariate system, although we focus on remittances. ${ }^{5}$ We present the relationship between the DFM with the factor representation of cointegrated time series.

\footnotetext{
${ }^{5}$ See Stock and Watson (1988) and Vahid and Engle (1993) for other but related small common factors representations.
} 


\subsection{Dynamic Factor Model for the Mexican Remittances: P-T Decom- position}

Traditionally, the literature distinguishes between small and large DFM related with the number of variables and their respective number of observations. Furthermore, there are some differences between static factor models and DFM, primarily given by the process that generates the common factors, the individual effects and/or the relationship between the possible lags of the factors and the observed variables. ${ }^{6}$ Bai and $\mathrm{Ng}$ (2007) show how a static factor model can be expressed as a DFM. Because of this, we do not distinguish between both models. The basic DFM can be written as follows:

$$
Y_{t}=P F_{t}+\varepsilon_{t}
$$

where $Y_{t}=\left(y_{1 t}, \ldots, y_{N t}\right)^{\prime}$ is the $N \times 1$ vector of observations, $P$ is the loading matrix of size $N \times s$ with $s<N, F_{t}$ is the $s$-dimensional vector of common factors and $\varepsilon_{t}$ are the individual effects over each variable. The main idea of this DFM is that the time series, $Y_{t}$, is driven by common factors, $F_{t}$, where the loading effect is represented by $P$, plus individual effects, $\varepsilon_{t}$, which can be more or less important with respect to the common components, $P F_{t}$.

Structurally, remittances are clearly related with the economic behaviour of the migrant's home and host economies, as well as with the exchange rate between both sending and recipient countries, in the sense that it is a variable that captures to a large degree the saving decisions of the migrant. We split economic activity of the host country into industrial production and the unemployment rate, to capture the particular effects of each variable. Other variables such as the inflation rate, the spread of the interest rates between both countries, relative wages, stock or flow of migrants, and the unemployment rate of the home country, among others, are not considered because the expected sign is doubtful or because of data availability constrains.

Therefore, in our factor representation the number of variables is $N=5$, being a small DFM with $Y_{t}=\left(x_{t}, y_{t}^{d}, y_{t}^{h}, e_{t}, u_{t}^{h}\right)^{\prime}$, where $x_{t}$ represents the monthly flow of remittances, $y_{t}^{d}$ denotes GDP of the home economy, $y_{t}^{h}$ the industrial production index of the host economy, $e_{t}$ the real exchange rate between the home and the host economies, and $u_{t}^{h}$ captures the unemployment rate of the host economy. We expect that the home economy

\footnotetext{
${ }^{6}$ See Poncela and Ruiz (2016) for a review of the sample performance of several methods of estimation.
} 
has a long-run permanent growth rate which tends to decrease remittances. On the other hand, if $y_{t}^{h}$ grows permanently in the long-run it benefits the flow of remittances, since a real depreciation of the home currency tends to increase remittances because it is more profitable to send remittances from the host economy. Finally, the sign of $u_{t}^{h}$ depends on the particular economic conditions between both countries. In this study, we refer to Mexico as the home economy and the U.S. as the host economy.

Following Bai and $\mathrm{Ng}$ (2004) in small DFM, the analysis of cointegration, common trends and cycles, the estimation methodology typically used depends on whether the variables considered are all $I(1)$ or $I(0)$. Subsequently, Eq. (1) is adapted to the factor representation given by Gonzalo and Granger (1995) taking into account the following issues:

1. The elements of $Y_{t}$ are cointegrated. ${ }^{7}$ This implies that in the DFM (1) $Y_{t} \sim I(1)$ and consequently $F_{t}$ is also $I(1), \varepsilon_{t} \sim I(0)$ and $P$ is distinct from zero. Also, $\beta^{\prime} Y_{t}$ is the cointegration relationship where $\beta$ is the $r \times 1(r<N)$ cointegration vector.

2. $Y_{t}$ follows a VECM representation as follows:

$$
\Delta Y_{t}=\alpha \beta^{\prime} Y_{t-1}+\sum_{i=1}^{\infty} \Xi_{i} \Delta Y_{t-i}+u_{t}
$$

3. The common factors, $F_{t}$ is a vector of size $s=N-r$ and is a linear combination of the variable, $Y_{t}$, that we can represent through the following expression:

$$
F_{t}=B Y_{t}
$$

4. FM (1) is a P-T decomposition according to the definitions given by Quah (1992). These definitions are related with the long-run effects which have the factor and idiosyncratic noises with respect to the observed variables.

In order for the last point to be valid, it is necessary that the traditional assumptions in DFM hold. ${ }^{8}$ Nonetheless, we relax the assumption of strong pervasive factors, i.e. we do not assume that the cumulative effect of the least influential factor rises proportionally

\footnotetext{
${ }^{7}$ Additionally, note that a priori it is necessary that the series in $Y_{t}$ are cointegrated. If the time series are not cointegrated, the estimation of common factors can be carried out by several procedures. See Poncela and Ruiz (2016) for a review of the literature.

${ }^{8}$ See Bai and Ng (2002) and Stock and Watson (2002a) who indicate that $\operatorname{var}\left(\Delta F_{t}\right)$ and $\operatorname{var}\left(\varepsilon_{t}\right)$ must exist.
} 
to $N$. Hence, the variance structure is similar to Onatski (2012). The dynamic of the common factors and the idiosyncratic terms are introduced as follows:

$$
\left(\begin{array}{cc}
\Phi(L) & 0 \\
0 & \Gamma(L)
\end{array}\right)\left(\begin{array}{c}
\Delta F_{t} \\
\varepsilon_{t}
\end{array}\right)=\left(\begin{array}{c}
\eta_{t} \\
a_{t}
\end{array}\right)
$$

where $\Phi(L)$ are the $s \times s$ polynomial matrices of the autoregressive process of the stationary common factors and $\Gamma(L)$ contains the $N \times N$ matrices for each lag of the individual components. Additionally, $\eta_{t}$ and $a_{t}$ represent factor disturbances and the error term for the individual effects. Eqs. (1) and (4) form the small DFM, where it is required that the following conditions are satisfied in order to obtain a P-T decomposition:

$$
\begin{aligned}
& \lim _{h \rightarrow \infty}=\frac{\partial E_{t}\left(Y_{t+h}\right)}{\partial \eta_{t}} \neq 0, \\
& \lim _{h \rightarrow \infty}=\frac{\partial E_{t}\left(Y_{t+h}\right)}{\partial a_{t}}=0,
\end{aligned}
$$

where $E_{t}$ is the expected value conditional on past history. In other words, if only the shocks of the common component affect the prediction of the observations, the proposed DFM is a permanent and transitory P-T decomposition.

Note that substituting Eq. (3) in $(1) \varepsilon_{t}=(I-P B) Y_{t}$ so that, we can express the individual effects in terms of a equilibrium relationship as $\varepsilon_{t}=P^{*} \beta^{\prime} Y_{t}$, i.e. the linear combination of variables that do not contain long-run effects. On the other hand, the orthogonal complement of the error correction term is $\alpha_{\perp}$ of size $N \times s$, i.e. the linear combination of variables that contains common features of the observed variables. In this case, the $I(1)$ common factors are given by:

$$
F_{t}=\alpha_{\perp}^{\prime} Y_{t}
$$

Note that $F_{t}$ represent the common non-stationary trends. Finally, the small DFM can be re-written as follows:

$$
Y_{t}=P \alpha_{\perp}^{\prime} Y_{t}+P^{*} \beta^{\prime} Y_{t}=P F_{t}+\varepsilon_{t}
$$

where $P=\beta_{\perp}\left(\alpha_{\perp}^{\prime} \beta_{\perp}\right)^{-1}$ and $P^{*}=\alpha\left(\beta^{\prime} \alpha\right)^{-1} \cdot{ }^{9}$

\footnotetext{
${ }^{9}$ For further details on the existence of the DFM given by Eq. (7) see Gonzalo and Granger (1995)
} 


\subsection{Estimation}

In large DFM the traditional procedure to estimate the non-stationary common components and the individual effects are frequently determined by PC (see, e.g. Bai, 2004, Bai and Ng, 2004, Choi, 2012, Banerjee et al., 2014). It is important to note that in large DFM the assumptions to obtain a consistent estimation of $P F_{t}$ are asymptotic, requiring that when $N$ tends to infinity the eigenvalues of $P \Sigma_{F} P^{\prime}$ grow to rate $N$ while the eigenvalues of $\Sigma_{\varepsilon}=E\left(\varepsilon_{t} \varepsilon_{t}^{\prime}\right)$ remain bounded, where $\Sigma_{F}$ and $\Sigma_{\varepsilon}$ are the covariance matrices of the factors and the idiosyncratic terms, respectively. The estimation is carried out imposing $F^{\prime} F / T=I_{s}$ or $P^{\prime} P / N=I_{s}$ where $F=\left(F_{1 t}, \ldots, F_{s t}\right)^{\prime}$.

In order for the DFM to be a P-T decomposition, it is necessary to impose the long-run equilibrium restrictions presented in the previous subsection. In the context of the small DFM which is a $\mathrm{P}-\mathrm{T}$ decomposition, the estimation of $F_{t}, P$ and $P^{*}$ directly depend on the cointegration exercise. In this case we consider the estimation of a VECM given by Eq. (2), focusing on the matrix $\Pi=\alpha \beta^{\prime}$. Following Johansen $(1988,1991)$, the estimation of $\Pi$ requires, first, the regression between $\Delta Y_{t}$ and $Y_{-1}$ on $\left(\Delta Y_{t-1}, \ldots, \Delta Y_{t-(k-1)}\right)$, with the purpose of obtaining the residuals $R_{0 t}$ and $R_{1 t}$ respectively, which are necessary to generate the following matrices:

$$
S_{i j}=T^{-1} \sum_{i=1}^{T} R_{0 t}, \quad \text { for } \quad i=0,1 .
$$

Solving the following eigenvalues problem, we can obtain the estimator of the cointegration vector:

$$
\left|\lambda S_{11}-S_{10} S_{00}^{-1} S_{01}\right|=0
$$

for eigenvalues $\hat{\lambda}_{1}>\ldots>\hat{\lambda}_{N}$ and eigenvectors $\hat{V}=\left(\hat{v}_{1} \ldots \hat{v}_{N}\right)$. The maximum likelihood estimators are given by $\hat{\beta}=\left(\hat{v}_{1} \ldots \hat{v}_{r}\right), \hat{\alpha}=S_{01} \hat{\beta}$ and $\hat{\Lambda}=S_{00}-\hat{\alpha} \hat{\alpha}^{\prime}$. Assuming in Eq. (2) that $u_{t} \sim \mathrm{MN}(0, \Lambda)$ and following Gonzalo and Granger (1995), the maximum likelihood function to maximise in order to find the estimator of $\beta_{\perp}$ is given by:

$$
L_{\max }^{-2 / T}=|\hat{\Lambda}|=\left|S_{00}\right| \prod_{i=1}^{r}\left(1-\hat{\lambda}_{i}\right)
$$

who, similarly to Bai (2004), impose stationarity conditions over the common factors (in first-differences) and the individual effects. 
Under the hypothesis of cointegration, the maximum likelihood estimator of $\beta_{\perp}$ is found solving the following equation:

$$
\left|\lambda S_{00}-S_{01} S_{11}^{-1} S_{10}\right|=0
$$

Giving the eigenvalues $\hat{\lambda}_{1}>\hat{\lambda}_{2} \ldots>\hat{\lambda}_{N}$ and the eigenvectors $\hat{M}=\left(\hat{m}_{1}, \hat{m}_{2} \ldots \hat{m}_{N}\right)$, normalised such that $\hat{M}^{\prime} S_{0,0} \hat{M}=I$, the estimator that maximised Eq. (10) is as follows:

$$
\hat{\alpha_{\perp}}=\left(\hat{m}_{r+1}, \hat{m}_{2} \ldots \hat{m}_{N}\right) \text {. }
$$

This estimator and the corresponding of $\Pi$, we allows consistently determine the $P, F_{t}$ and $P^{*}$ and consequently, the permanent and transitory components or in the context of DFM, the loading matrix, the non-stationary common factors and the individual effects.

\section{Results}

In this section we describe the data used in the empirical analysis, the stochastic properties, the estimation of the small DFM, and finally we analyse the P-T decomposition for each variable of the system.

\subsection{Data}

Monthly data is obtained from Banco de México (Bank of Mexico) and the Instituto Nacional de Geografía y Estadística (INEGI, National Institute of Geography and Statistics) from January 1995 to March 2015, so that $N=5$ and $T=243$. The variables used in the study are the following:

- Total remittances $\left(x_{t}\right)$ : Constituted by money orders, personal checks, electronic transfers and cash sent from the U.S. to Mexico. The variable is in millions of U.S. dollars and is seasonally adjusted.

- Home economic activity $\left(y_{t}^{d}\right)$ : Measured by the Indicador Global de la Actividad Económica (IGAE, Global Index of Economic Activity), it is a monthly proxy of GDP that captures the activity of the primary, secondary and tertiary sectors of the Mexican economy. The base year of the index is 2008. We consider the seasonally 
adjusted time series. ${ }^{10}$

- Industrial production of the host country $\left(y_{t}^{h}\right)$ : This index includes the production of goods and services of the mining sector, manufacturers, electricity, gas and water in the U.S. The base year of the index is 2010 and it is seasonally adjusted.

- Real bilateral exchange rate $\left(e_{t}\right)$ : Constituted by the relative price of goods between the home economy, i.e. Mexico, and the host economy, i.e. the U.S., it is composed as follows:

$$
\frac{E p^{*}}{p}
$$

where $E$ is the nominal exchange rate of Mexican pesos for U.S. dollars, $p^{*}$ is the consumer price index of the U.S and $p$ is the consumer price index of Mexico, both with base year of 2010 .

- Unemployment rate of host country $\left(u_{t}^{h}\right)$ : Percentage of the economically active population in the U.S. that is unemployed.

The series are expressed in logarithms and standardised with zero mean and unit variance, following common procedure in DFM. Moreover, while $y_{t}^{d}$ and $y_{t}^{h}$ have different base year, this has no effect on the common features which is the element of main interest in this study.

\subsection{Unit Root Tests}

Figure 1 plots the series in levels and in first differences. The top panel represents $x_{t}$, followed by $y_{t}^{d}, y_{t}^{h}$ and $e_{t}$, while the bottom panel shows $u_{t}^{h}$. The left panel shows the time-series in levels and the right panel in first differences.

Figure 1 about here

The time-series exhibit trends which disappear in first differences. This is also true for $e_{t}$, which starting in 2009 exhibited a change of level similar to that of $u_{t}^{h}$. Moreover, in first differences we can see as the volatility of $e_{t}$ is larger than that of the other variables, but seems to be around a constant mean. Descriptively, these behaviours are typically of $I(1)$

\footnotetext{
${ }^{10}$ The linear correlation between the growth of IGAE and the growth of GDP is 1.
} 
series, but it is nonetheless necessary to perform the formal tests. For this, we propose the Kwiatkowski-Phillips-Schmidt-Shin (KPSS) test and the Augmented Dickey-Fuller (ADF) test. Table 1 presents the results.

Table 1 about here

Although the ADF test indicates that $y_{t}^{h}$ and $e_{t}$ are stationary in levels, the KPSS test rejects the null hypothesis of stationarity. ${ }^{11}$ It can be seen that the tests corroborate what is observed in the plot, which is that the variables are stationary in first differences. ${ }^{12}$

\subsection{Small DFM: Cointegration Analysis and Common Factors}

The cointegration analysis is required for the estimation of the small DFM. Therefore, it is necessary that the series are cointegrated. In order to evaluate the cointegration we use the Johansen (1991) procedure. Firstly, it is necessary to estimate a Vector Autoregressive (VAR) ${ }^{13}$ which is specified with constant and lag length, $K=5$, according to the Akaike Information Criterion (AIC). ${ }^{14}$ Table 2 shows the results of the cointegration test. ${ }^{15}$

Table 2 about here

The results indicate that there exists a $r=1$ cointegration equation at the $5.0 \%$ significance level. We normalised the cointegration equation for $x_{t}$, where t-statistics are presented in parenthesis, and which is given by:

$$
x_{t}=\underset{(-4.79)}{-5.52} y_{t}^{d}+\underset{(6.41)}{7.19} y_{t}^{h}+\underset{(5.78)}{1.73} e_{t}+\underset{(4.90)}{2.42} u_{t}^{h}+z_{t},
$$

The coefficients can be interpreted as pseudo-elasticities given that the variables are stan-

\footnotetext{
${ }^{11}$ Furthermore, we apply the Busetti and Harvey (2001) test, which is a modification of the KPSS test that allows incorporating multiple structural breaks. The results do not differ from the ones obtained with the KPSS test.

${ }^{12}$ The conclusion of the test is obtained analysing the p-values, which are interpolated from Table 4.2 of Banerjee et al. (1993). The specification of the test is automatised using the package "tseries" taken from https://cran.r-project.org/web/packages/tseries/tseries.pdf. Alternatively, we also consider the U.S. unemployment rate without applying the natural logarithm given that the series is by definition a percentage. The results obtained under this econometric approach are very similar.

${ }^{13}$ We implement the Granger causality test. The endogeneity of the VAR in levels shows that all variables are mutually causal with the exception of the unemployment rate. Moreover, instant causality denotes the presence of causality. Nevertheless, these findings are completely descriptive because the series are non-stationary.

${ }^{14}$ Alternatively, we test Bayesian Information Criterion (BIC) and HQ criteria obtaining for the BIC = 2 and $\mathrm{HQ}=3$. We decided to use the AIC because it allows analysing more contemporaneous dynamics.

${ }^{15} \mathrm{We}$ use the maximum eigen value test. The specification of the cointegration equation is without constant and trend. We use the log-likelihood statistic to decide this specification.
} 
dardised. The magnitude indicates the weights of each variable over remittances in the long-run. Note that all coefficients are significant at 1.0\%. ${ }^{16}$ We can see that the industrial production of the host economy is positively related with the flow of remittances, while a better economic performance of the home economy decreases the amount of remittances received in the long-run. On the other hand, a depreciation of the home currency increases the flow of remittances. A similar relationship is observed regarding the unemployment rate of the host economy. It may be that the synchronisation of the labour markets causes that the unemployment rate of the host economy pulls the demand of Mexican labour, encouraging that a larger number of workers be inserted into the U.S. As an example, in the long-run, if all variables were to rise $1.0 \%$ the flow of remittances would increase by $3.6 \%$.

The $N-r$ common factors are given by the following expression:

$$
F_{t}=\left(\begin{array}{ccccc}
2.95 & 18.29 & 1.62 & -2.05 & -3.12 \\
-7.84 & 1.11 & 7.79 & -0.31 & -0.77 \\
-2.65 & 5.12 & -11.18 & -1.78 & 4.25 \\
-2.38 & 12.86 & -10.03 & 2.65 & -4.42
\end{array}\right)\left(\begin{array}{c}
x_{t} \\
y_{t}^{d} \\
y_{t}^{h} \\
e_{t} \\
u_{t}^{h}
\end{array}\right)
$$

Given that $s=N-r=4$, we have four common trends.

The coefficients of the loading matrix indicate that we have non-stationary common factors with positive and negative trends, where $y_{t}^{d}$ and $y_{t}^{h}$ present dominate trends. For instance, the first non-stationary common factor $F_{1 t}=2.95 x_{t}+18.29 y_{t}^{d}+1.62 y_{t}^{h}-2.05 e_{t}-$ $3.12 u_{t}^{h}$ indicates that remittances are driven by the activity of the Mexican economy, where the real exchange rate and the unemployment rate of the U.S. follow a negative trend within the factor. Additionally, it can be seen that in the second common factor only the variables of economic activity are positive, finding a trade-off between remittances and the U.S. economy. In the third factor, the economic activity of the U.S. is widely negative. Finally, the fourth factor is a trade-off between the economic activity of both countries, because the loading of Mexico is 12.86 while for the U.S. it stands -10.03 .

Figure 2 plots the non-stationary common factors. With respect to the behaviour of the factors, we can see that the first factor has the pattern of growth given by the Mexican

\footnotetext{
${ }^{16}$ We carry out the serial correlation and ARCH effect tests in the VECM representation. Both tests do not allow us to reject the null hypothesis with p-values of 0.10 and 0.26 , respectively.
} 
economy. The second factor presents a fall in the crisis period because both economies contracted during this time. The third factor has an opposite pattern with respect to the first factor because the U.S. economic activity has an important effect. The fourth factor seems to exhibit a trade-off between the Mexican and the U.S. economy. These non-stationary common factors allow us to recover the permanent effects. On the other hand, the cointegration vector allows us to estimate the transitory components.

Figure 2 about here

Note that this approach detects four common trends or common factors. Studying the

behaviour of the eigenvalues of $\hat{\Sigma}_{Y}=\sum_{t=1}^{T} Y_{t} Y_{t}^{\prime} / T$, denoted as $\lambda_{i}$ for $i=1, \ldots, 5$, we can approximate the number of common factors as in a traditional DFM. We use $\lambda_{i} / \lambda_{i+1}$ following Ahn and Horenstein (2013) in the context of large DFM. The maximum value of this ratio tends to approximate the number of common factors. Figure 3 plots the results.

Figure 3 about here

It can be seen that $\max \left\{i \mid\left(\lambda_{i} / \lambda_{i+1}\right)\right\}$ is obtained in $i=4$, so that, we obtain the equal number of common factors. These non-stationary common factors allow us to recover the permanent effects. The cointegration vector estimates the transitory components.

\subsection{Remittances: Permanent and Transitory Components}

Once estimated, the non-stationary common factors, $F_{t}$, and the cointegration vector, $z_{t}$, the $\mathrm{P}-\mathrm{T}$ decomposition is completed estimating the loading matrices $P$ and $P^{*}$ which are the following:

$$
P=\left(\begin{array}{rrrr}
0.04 & -0.10 & -0.03 & -0.02 \\
0.05 & 0.00 & 0.03 & 0.02 \\
0.03 & 0.02 & -0.02 & -0.02 \\
-0.02 & -0.09 & -0.02 & 0.14 \\
0.04 & -0.05 & 0.12 & -0.03
\end{array}\right) \text {. }
$$




$$
P^{*}=\left(\begin{array}{c}
-0.04 \\
-0.08 \\
-0.07 \\
-0.38 \\
-0.27
\end{array}\right) \text {. }
$$

Focusing on the $\mathrm{P}-\mathrm{T}$ decomposition of $x_{t}$, in this context the permanent component is given by $x_{t}^{\mathrm{P}}=0.04 F_{1 t}-0.10 F_{2 t}-0.03 F_{3 t}-0.02 F_{4 t}$. It is observed that remittances grow only with the first factor and decrease with the rest of the factors. Analysing each sign of the different common factors, the flow of remittances grow as a linear combination of the common trends of the economy, which is associated to downturns of the domestic economy, growth of the host economy, devaluation of the currency and growth of the unemployment rate of the host economy. The transitory effects are an inverse weight of the long-run equilibrium relationship, and in this case are given by $x_{t}^{\mathrm{T}}=-0.04 x_{t}-0.12 y_{t}^{d}+0.19 y_{t}^{h}+$ $0.05 e_{t}+0.06 u_{t}^{h}$, i.e. -0.04 times the cointegration relationship. This result suggests that the convergence of the long-run equilibrium is slow.

We rescaled the variables in their original levels. Figure 4 shows the non-observable components of remittances.

Figure 4 about here

We can see that the flow of remittances is over its historical levels, i.e. given the economic conditions, the actual level of remittances surpasses its potential behaviour. This finding is important since it indicates that this economic input grows over its possibilities. Specifically, around 132 million U.S. dollars in December 2014; and 121, 115 and 127 million U.S. dollars in January, February and March 2015, respectively, above its permanent component. On the other hand, the historical minimum was reached in September 2008, around the start of the world financial crisis. Denoting the transitory equation, this indicates an accumulated effect of $-0.04 x_{t}-0.12 y_{t}^{d}+0.05 e_{t}^{x}<0.19 y_{t}^{h}+0.05 e_{t}$, showing that the economic growth of the U.S. plus the devaluation of the Mexican peso is larger than the economic growth of Mexico, the increase of the unemployment rate of the U.S. and a fraction of remittances.

The dynamics of remittances depend on the trade-off between the U.S. and Mexican 
economies. In other words, if Mexico's economy grows, the flow of remittances tends to decrease. If U.S. industrial production grows, the flow of remittances tends to increase. We can see that the long-run behaviour of Mexican remittances is dominated by the industrial production index of the U.S., which is almost 1.67 units larger than the effect of the domestic economy. The composition of the common factors denote that the common trends exhibit a similar pattern. This shows that the depreciation of the exchange rate and the increase of the U.S. unemployment rate positively affect the flow remittances. The direct relationship between the unemployment rate and the flow of remittances may be signalling that upon sensing higher risks in the labour market, Mexican migrants increase the amount of remittances sent to those left behind in Mexico as either a measure of precautionary saving or to guarantee their ability to meet future commitments back home. Nonetheless, the economic trade-off between both economies is the most relevant factor.

This conclusion is important given that, although there are other econometric studies that use several macroeconomic variables, the transitory and permanent effects of remittances can be summarised with these two variables of economic activity. We can see that the permanent component is very close to the flow of remittances, with the exception of the last period where the transitory effects are more volatile. This effect may be attributed to the improvement of the U.S. economy, the recession of the Mexican economy and the growth of the exchange rate.

\section{Conclusions}

This study estimated a small DFM to determine the permanent and transitory dynamics of Mexican remittances. The economic variables included in the system were selected according to the relevant literature, where the analysis shows that the most important variables are those related with the economic decisions to migrate. In this way, we analysed the multivariate effects shared with home economic activity, the industrial production index of the host country, the real bilateral exchange rate and the unemployment rate of the host country. Specifically, the factor model representation was estimated using the P-T decomposition proposed by Gonzalo and Granger (1995) which, subject to the cointegration results, determines the number of common factors or common trends. Moreover, the theoretical and statistic analogies between the proposed model and the large DFM were also described. 
Based on the econometric methodology used, it can be observed that remittances and the rest of the variables included in the study share a cointegration relationship. Consequently, there are $N-r=4$ common trends. This result is corroborated descriptively by analysing the ratio of the eigenvalues of the sample covariance matrix as usually is carried out in large DFM.

The first common factor is dominated for the Mexican economy, the second common factor for remittances and for the U.S. economy, the third common factor for the U.S. economy, and the fourth is a trade-off between both economies. This model allows analysing the permanent and transitory effects for each variable of the system. Focusing on remittances and the signs of the permanent equation, the behaviour of both economies mainly affects the dynamics of remittances, encouraging an increase in flows when the U.S. economy grows and the Mexican economy decreases. This implies that the real bilateral exchange rate and the unemployment rate of the host economy are less important in the permanent dynamic of remittances.

The transitory effects, i.e. the deviation between remittances and the permanent component, show that the actual level of remittances surpasses its potential behaviour, which is totally attributed to the short-run. For an interpretation about the duration of the transitory shocks for remittances we can analyse the response-impulse function of the VECM. In this study, we examined the behaviour of the unobserved components.

Avenues for further research include incorporating additional variables to estimate a large DFM and analysing the contribution of remittances in the common trends or in the business cycle. These common trends can be used to forecast the flow of remittances, similar to the procedure carried out by Stock and Watson (2005), based on the same macroeconomic variables for the case of the U.S.

\section{References}

Ahn, S. and A. Horenstein (2013). "Eigenvalue ratio test for the number of factors". Econometrica 81(3), 1203-1227.

Alessi, L., M. Barigozzi, and M. Capasso (2010). "Improved penalization for determining the number of factors in approximate factor models". Statistics and Probability Letters 80(1), 1806-1813. 
Bai, J. (2003). "Inferential theory for factor models of large dimensions". Econometrica $71(1), 135-171$.

Bai, J. (2004). "Estimating cross-section common stochastic trends in nonstationary panel data". Journal of Econometrics 122(1), 137-183.

Bai, J. and S. Ng (2002). "Determining the number of factors in approximate factor models". Econometrica 70(1), 191-221.

Bai, J. and S. Ng (2004). "A PANIC attack on unit roots and cointegration". Econometrica 72(4), 1127-1177.

Bai, J. and S. Ng (2007). "Determining the number of primitive shocks in factor models". Journal of American Statistical Association 25(1), 52-60.

Bai, J. and S. Ng (2008). "Large dimensional factor analysis". Foundations and Trends in Econometrics 3(2), 89-163.

Banerjee, A., J. Dolado, W. Galbraith, and D. Hendry (1993). Cointegration, Error Correction, and the Econometric Analysis of Non-Stationary Data. Oxford: Oxford University Press.

Banerjee, A., M. Marcellino, and I. Masten (2014). "Forecasting with factor-augmented error correction models". International Journal of Forecasting 30(1), 589-612.

Barro, R. (1974). "Are government bonds net wealth?". Journal of Political Economy 82(6), 1095-1117.

Becker, G. (1974). "A theory on social interactions". Journal of Political Economy 82(6), 1063-1093.

Bernheim, D., A. Shleifer, and L. Summers (1985). "The strategic bequest motive". Journal of Political Economy 93(6), 1045-1076.

Breitung, J. and I. Choi (2013). "Factor models". Handbook of Research Methods and Applications in Empirical Macroeconomics, Chapter 11, 249-265.

Busetti, F. and A. Harvey (2001). "Testing for the presence of a random walk in series with structural breaks". Journal of Multivariate Time Series 22(2), 127-150. 
Castillo, R. (2001). "Remesas: Un análisis de cointegración para el caso de México". Frontera Norte 13(26), 31-50.

Castillo, R., M. Rodríguez-Espinosa, and E. García-Meneses (2011). "The importance of macroeconomic conditions on remittances in the long-run and in the short-run: The case of Mexico". Applied Econometrics and International Development 11(1), 79-91.

Choi, I. (2012). "Efficient estimation of nonstationary factor models". Working Papers, Research Institute for Market Economy, Sogang University 1101.

Coronado, R. A. (2009). "Business cycles and remittances: Can the Beveridge-Nelson decomposition provide new evidence?". Working Paper Federal Reserve Bank of Dallas Globalization and Monetary Policy Institute 40.

Durand, J., E. Parrado, and D. Massey (1996). "International migration and development in Mexican communities". Demography 33(2), 249-264.

Elbadawi, I. and R. Rocha (1992). "Determinants of expatriate workers' remmitances in North Africa and Europe". World Bank Policy Research Working Paper 1038.

Engle, R. and M. Watson (1981). "A one-factor multivariate time series model of metropolitan wage rates". Journal of the American Statistical Association 76, 774781.

Engle, R. and M. Watson (1983). "Alternative algorithms for estimation of dynamic MIMIC, factor, and time varying coefficient regression models". Journal of Econometrics 23, 385-400.

Forni, M., M. Hallin, M. Lippi, and L. Reichlin (2000). "The generalized dynamic-factor model: Identification and estimation". Review of Economics and Statistics 82(4), 540554.

Forni, M., M. Hallin, M. Lippi, and L. Reichlin (2004). "The generalized factor model: Consistency and rates". Journal of Econometrics 119(1), 231-255.

Forni, M., M. Hallin, M. Lippi, and L. Reichlin (2005). "The generalized dynamic factor model: One-sided estimation and forecasting". Journal of the American Statistical Association 100(1), 830-840. 
Geweke, J. (1977). "The dynamic factor analysis of economic time series". Latent Variables in Socio-Economic Models, Amsterdam: North-Holland, 365-382.

Gonzalo, J. and C. W. J. Granger (1995). "Estimation of common long-memory components in cointegrated systems". Journal of Business and Economic Statistics 13(1), $27-35$.

Hanson, G. (2010). "Why isn’t Mexico rich?". Journal of Economic Literature 48(4), 987-1004.

INEGI (2015). "Banco de Información Económica. Aguascalientes: Instituto Nacional de Geografía y Estadística".

Islas, A. and S. Moreno (2011). "Determinantes del flujo de remesas en México, un análisis empírico". EconoQuantum 7(2), 9-36.

Jensen, R. (2003). "Do private transfers "displace" the benefits of public transfers? Evidence from South Africa". Journal of Public Economics 88(1-2), 89-112.

Johansen, S. (1988). "Statistical analysis of cointegration vectors". Journal of Economic Dynamics and Control 12(1), 231-254.

Johansen, S. (1991). "Estimation and hypothesis testing of cointegrating vectors in Gaussian vector autoregressive models". Econometrica 59(1), 1551-1580.

Juarez, L. (2009). "Crowding out of private support to the elderly: Evidence from a demogrant in Mexico". Journal of Public Economics 93(3-4), 454-463.

Kunst, R. and K. Neusser (1997). "Cointegration in a macroeconomic system". Journal of Applied Econometrics 5(1), 351-365.

Lam, C. and Q. Yao (2011). "Estimation of latent factors using high-dimensional time series". Biometrika 98(4), 901-918.

Lam, C. and Q. Yao (2012). "Factor modeling for high-dimensional time series: Inference for the number of factors". The Annals of Statistics 40(2), 694-726.

Lucas, R. and O. Stark (1985). "Motivations to remit: Evidence from Botswana". Journal of Political Economy 93(5), 901-918. 
Mendoza, J. E. (2011). Are remittances a stabilizing factor in the Mexican economy? EconoQuantum 9(1), 83-99.

Onatski, A. (2010). "Determining the number of factors from empirical distribution of eigenvalues". The Review of Economics and Statistics 92(4), 1004-1016.

Onatski, A. (2012). "Asymptotics of the principal components estimator of large factor models with weakly influential factors". Journal of Econometrics 168, 244-258.

Orraca, P. (2015). "Does access to free health insurance crowd-out private transfers? Evidence from Mexico's Seguro Popular". Latin American Economic Review 24(7), $1-34$.

Peña, D. and P. Poncela (2004). "Forecasting with nonstationary dynamic factor models". Journal of Econometrics 119(1), 291-321.

Peña, D. and P. Poncela (2006). "Non-stationary dynamic factor analysis". Journal of Statistical Planning and Inference 136(1), 237-257.

Poncela, P. and E. Ruiz (2016). "Small versus big data factor extraction in dynamic factor models: An empirical assessment in Dynamic Factor Models". Advances in Econometrics, 35, 401-434.

Quah, D. (1992). "The relative importance of the permanent and transitory components: Identification and some theoretical bounds". Econometrica 60, 107-118.

Quah, D. and T. Sargent (1993). "A dynamic index model for large cross sections, with discussion". Business Cycles, Indicators, and Forecasting, ed. by J.H. Stock and M.W. Watson, Chicago: University of Chicago Press for the NBER, 285-310.

Rosenzweig, M. (1988). "Risk, implicit contracts and the family in rural areas of lowincome countries". Economic Journal 98(393), 1148-1170.

Sargent, T. J. (1989). "Two models of measurements and the investment accelerator". Journal of Political Economy, 251-287.

Sargent, T. J. and C. A. Sims (1977). Business cycle modeling without pretending to have too much a priory economic theory. New Methods in Business Cycle Research Minneapolis: Federal Reserve Bank of Minneapolis. 
Stock, J. H. and M. W. Watson (1988). "Testing for common trends". Journal of the American Statistical Association 83(1), 1097-1107.

Stock, J. H. and M. W. Watson (1989). "New indexes of coincident and leading economic indicators". NBER Macroeconomics Annual, 351-393.

Stock, J. H. and M. W. Watson (2002a). "Forecasting using principal components from a large number of predictors". Journal of the American Statistical Association 97(1), $1169-1179$.

Stock, J. H. and M. W. Watson (2002b). "Macroeconomic forecasting using diffusion indexes". Journal of Business and Economic Statistics 20(1), 147-163.

Stock, J. H. and M. W. Watson (2005). "Implications of dynamic factor models for VAR analysis". NBER Working Paper $1146 \%$.

Stock, J. H. and M. W. Watson (2011). "Dynamic Factor Models, in Clements, M.P and D.F. Hendry (eds.) ". Oxford Handbook of Economic Forecasting, Oxford: Oxford University Press.

Vahid, F. and R. F. Engle (1993). "Common trends and common cycles". Journal of Applied Econometrics 8(1), 341-360.

Vargas-Silva, C. and P. Huang (2006). "Macroeconomic determinants of workers' remittances: Host versus home country's economic conditions". Journal of International Trade E Economic Development 15(1), 81-99.

World Bank (2015). "World Development Indicators. Washington, DC: World Bank". 


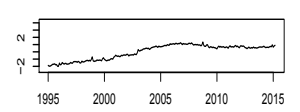

Time
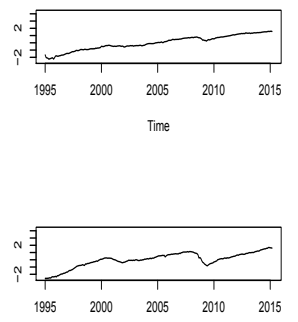

Time
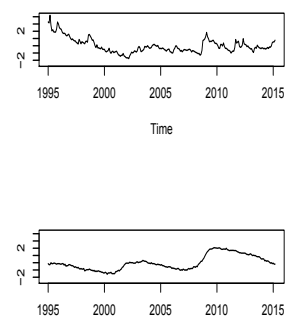
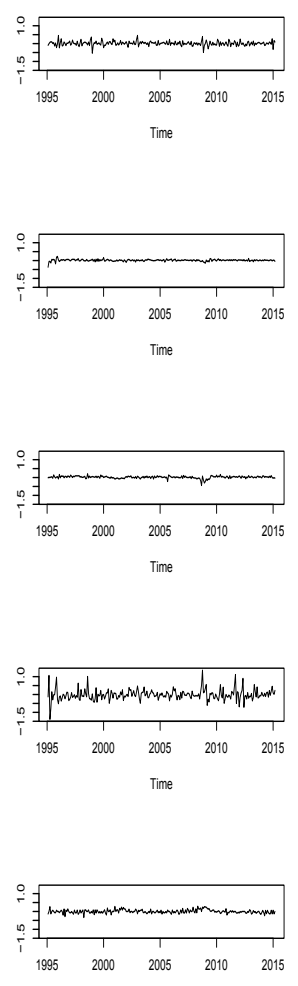

Figure 1: Left panel plots the time series in levels and right panel plots the time series in first differences. The top panel presents the total familiarly remittances, followed it for home economic activity, industrial production of the host country, real bilateral exchange and unemployment rate of host country. 

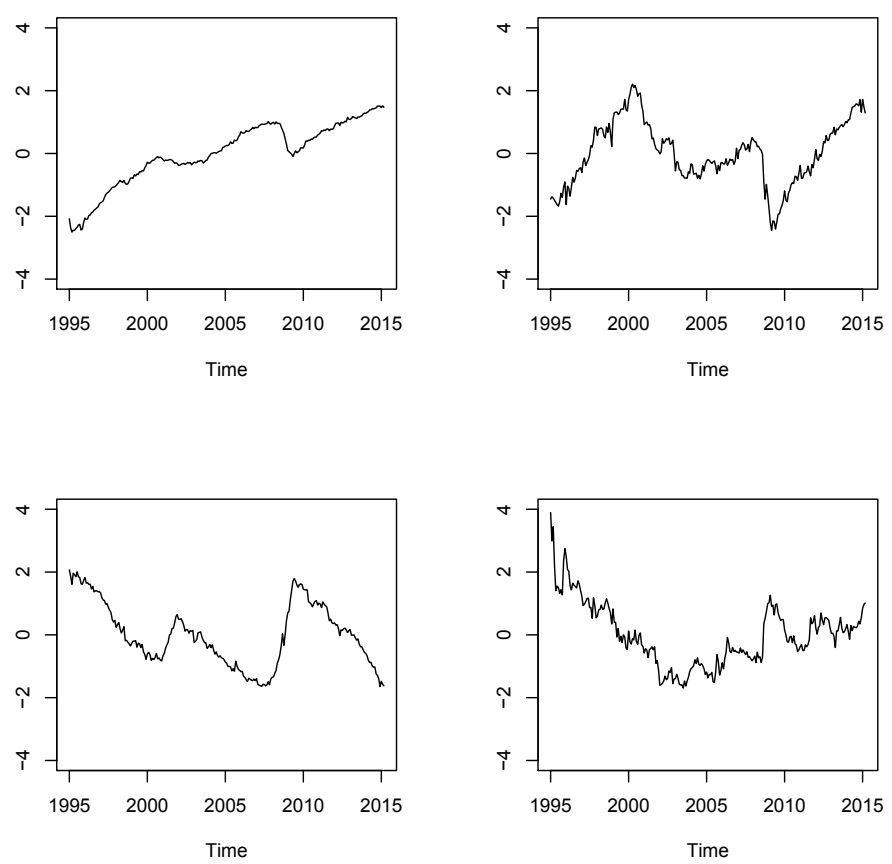

Figure 2: Estimated non-stationary common factors. Top-left panel is the first factor, top-right panel is the second factor, bottom-left panel the third factor and bottom-right the fourth factor.

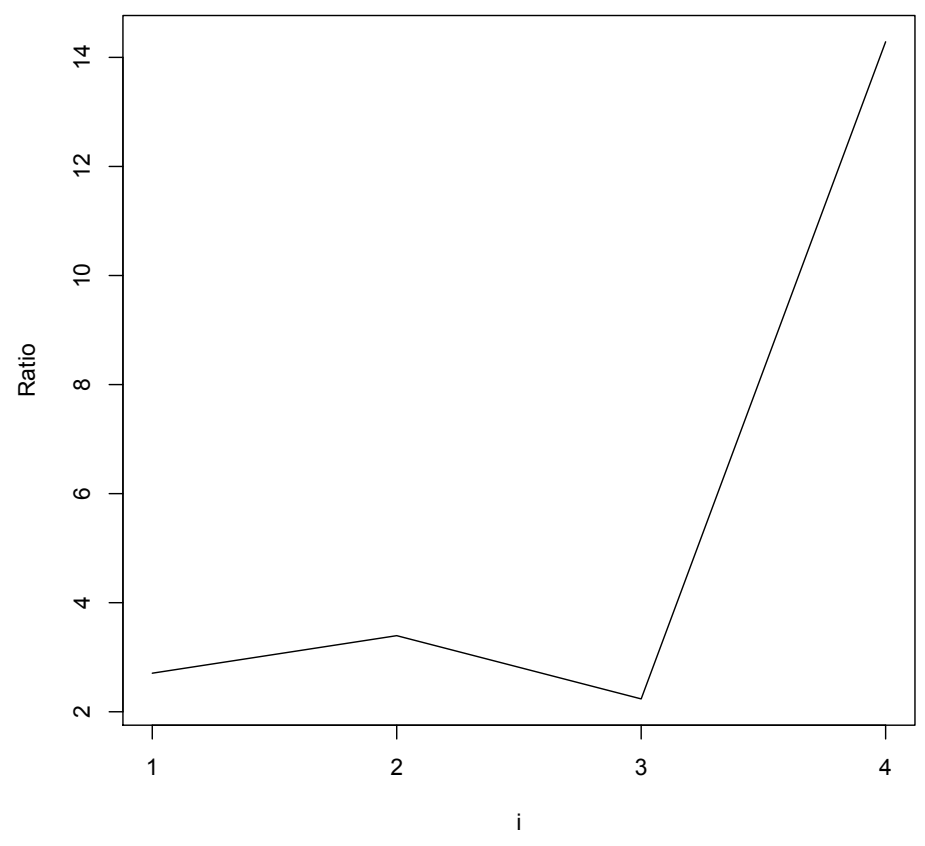

Figure 3: Ratio of eigenvalues of sample covariance matrix 

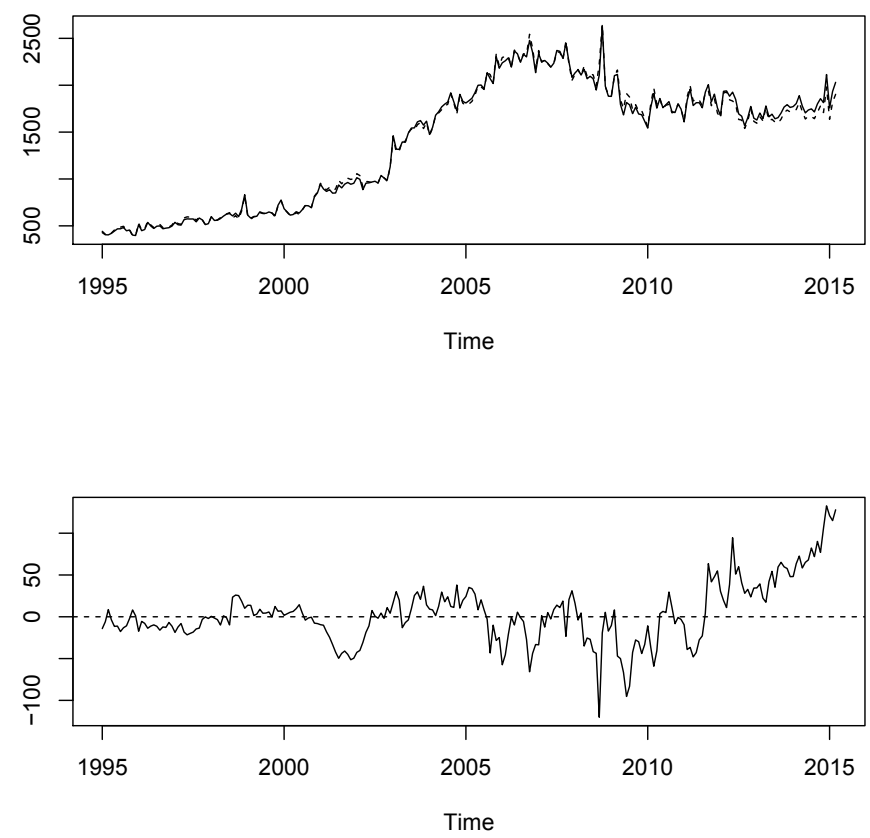

Figure 4: P-T decomposition for the total remittances. Top panel plots the observed series (line) and the permanent component (dotted). Bottom panel plots the transitory component.

Table 1: We present the value of the statistic test of each time series both levels and first differences accoding to each test. KPSS is the Kwiatkowski Phillips Schmidt Shin test and $\mathrm{ADF}$ is the Augmented Dicker Fuller test.

\begin{tabular}{cccc}
\hline \hline Serie & Test & Levels & First differences \\
\hline$x_{t}$ & KPSS & 5.04 & 0.27 \\
$y_{t}^{d}$ & KPSS & 5.82 & 0.06 \\
$y_{t}^{h}$ & KPSS & 3.85 & 0.34 \\
$e_{t}$ & KPSS & 1.46 & 0.24 \\
$u_{t}^{h}$ & KPSS & 3.05 & 0.28 \\
$x_{t}$ & ADF & -1.82 & -6.81 \\
$y_{t}^{d}$ & ADF & -3.86 & -5.07 \\
$y_{t}^{h}$ & ADF & -2.62 & -3.59 \\
$e_{t}$ & ADF & -2.71 & -7.67 \\
$u_{t}^{h}$ & ADF & -2.18 & -2.83 \\
\hline
\end{tabular}


Table 2: Maximum eiganvalue of cointegration test using $K=5$ and none specification in the equation cointegration.

\begin{tabular}{rrrrr}
\hline \hline & Test & 10pct & 5pct & 1pct \\
\hline$r \leq 4$ & 3.38 & 6.50 & 8.18 & 11.65 \\
$r \leq 3$ & 5.04 & 12.91 & 14.9 & 19.19 \\
$r \leq 2$ & 13.88 & 18.90 & 21.07 & 25.75 \\
$r \leq 1$ & 19.08 & 24.78 & 27.14 & 32.14 \\
$r=0$ & 44.20 & 30.84 & 33.32 & 38.78 \\
\hline
\end{tabular}

